\title{
MANFAAT BERENANG DAN TERAPI AIR PADA PERTUMBUHAN DAN PERKEMBANGAN BAYI \& BALITA
}

\section{THE BENEFITS OF SWIMMING AND WATER THERAPY IN GROWTH AND DEVELOPMENT OF BABY AND TODDLER}

\author{
Ervin Rufaindah \\ STIKES Widyagama Husada Malang \\ Email : ervinrufaindah@yahoo.com
}

\begin{abstract}
ABSTRAK
Pertumbuhan dan perkembangan mengalami peningkatan yang pesat pada usia dini, yaitu dari 0-5 tahun. Periode tumbuh kembang anak pada masa balita merupakan pertumbuhan dasar yang akan mempengaruhi dan menentukan perkembangan kemampuan berbahasa, kreatifitas, kesadaran sosial, emosional dan intelegensia yang berjalan dengan cepat serta merupakan landasan perkembangan berikutnya. Sebanyak $16 \%$ balita di Indonesia mengalami gangguan perkembangan, baik perkembangan motorik halus dan kasar, gangguan pendengaran, kecerdasan kurang dan keterlambatan. Metode yang digunakan adalah studi tinjauan literatur (literature review) meliputi studi pencarian sistematis database terkomputerisasi: EBSCOHOST, Google Scholar dan Pubmed dalam bentuk jurnal penelitian berjumlah 10 jurnal yang diterbitkan sejak tahun 2010-2014. 10 jurnal menggunakan metode kuantitatif. Studi literatur ini mencoba memaparkan tentang aktifitas di air seperti berenang dan terapi air untuk pertumbuhan dan perkembangan bayi balita. Hasil mneunjukkan berenang atau aktifitas air lainnya dapat meningkatkan kemampuan motorik kasar, motorik halus dan kemampuan bahasa pada balita. Berenang dan terapi air pada balita dapat bermanfaat untuk mendukung pertumbuhan dan perkembangan bayi dan balita.
\end{abstract}

Kata Kunci: Berenang, Terapi Air, Pertumbuhan Dan Perkembangan, Bayi Dan Balita

\section{ABSTRACT}

Growth and development has increased rapidly at an early age, ie from 0-5 years. The period of child development during infancy is a basic growth that will influence and determine the development of language skills, creativity, social awareness, emotional and intelligence that goes quickly and is the foundation of the next development. As many as $16 \%$ of children under five in Indonesia experience developmental disorders, both smooth and rough motor development, hearing loss, lack of intelligence and delays. The method used was literature review study which includes systematic search of computerized database: EBSCOHOST, Google Scholar and Pubmed in the form of research journal totaling 10 journals published since 2010-2014. 10 journals using quantitative methods. This literature study tried to explain about the activities in the water such as swimming and water therapy for the growth and development of infants. The result showed that swimming or other aquatic activities can improve gross motor skills, fine motor skills and language skills in toddlers. Swimming and water therapy in toddler can be beneficial to support the growth and development of baby and toddler.

Keywords : Swimming, Water Therapy, Growth And Development, Baby And Toddler

\section{PENDAHULUAN}

Pembangunan yang berkelanjutan di masa depan membutuhkan anak-anak bangsa yang cerdas dan sehat serta berkualitas

(ShamsB, 2013).

Pertumbuhan dan perkembangan anak dalam beberapa tahun pertama kehidupan merupakan indikator 
kesehatan yang sangat penting bagi anak-anak (Jeharsae R, 2013). Menurut Profil Kesehatan Indonesia tahun 2013 jumlah balita Indonesia sebanyak 23.700.676 jiwa (ID, 2012).

Pertumbuhan dan perkembangan mengalami peningkatan yang pesat pada usia dini, yaitu dari 0-5 tahun. Periode tumbuh kembang anak pada masa balita merupakan pertumbuhan dasar yang akan mempengaruhi dan menentukan perkembangan kemampuan berbahasa, kreatifitas, kesadaran sosial, emosional dan intelegensia yang berjalan dengan cepat serta merupakan landasan perkembangan berikutnya.

Pertumbuhan yang terhambat memiliki asosiasi yang kuat dengan mortalitas dan morbiditas pada anakanak usia dibawah lima tahun, sedangkan keterlambatan perkembangan terkait dengan gangguan perkembangan psiko-sosial dan intelektual dan kemampuan belajar mereka.

Lebih dari 200 juta anak usia kurang dari 5 tahun dari negara yang berpenghasilan rendah dan negaranegara berpenghasilan menengah mengalami gangguan tumbuh kembang, kualitas anak pada masa sekolah (Laura E. Murray-Kolb, 2014). Sebanyak 16\% balita di Indonesia mengalami gangguan perkembangan, baik perkembangan motorik halus dan kasar, gangguan pendengaran, kecerdasan kurang dan keterlambatan (Feti, t.thn.). Prevalensi gangguan perkembangan paling tinggi terjadi pada gangguan bahasa $(13,8 \%)$, kemudian diikuti oleh gangguan perkembangan motorik halus $(12,2 \%)$ (Heribert L Stich, 2012).

Selama bertahun-tahun, banyak penelitian telah menunjukkan bahwa aktifitas fisik memiliki manfaat untuk kesehatan mental, kognitif dan fisik. Meskipun setiap anak memiliki pola perkembangan yang unik, perkembangan dipengaruhi oleh interaksi antara pengalaman hidup dan lingkungan. Dengan demikian secara teoritis bahwa mengubah pelatihan lingkungan dari non air untuk air, dapat meningkatkan anak kemampuan, meningkatkan keterampilan yang ada dan / atau memperkenalkan hal yang baru. Bahkan, sepanjang sejarah, air telah digunakan selama bertahun untuk terapi fisik, olahraga, dan kesehatan fisik (Tsur Ronit Ram, 2013).

Dengan perkembangan standar hidup orang tua harus memperhatikan kesehatan anak. Berenang dan pijatan 
dapat mempromosikan pertumbuhan dan perkembangan bayi (Xiu-min Jiang, 2014). Melalui aktifitas dalam lingkungan air, anak bisa mendapat keterampilan baru seperti berenang, menyelam dan mengapung yang tidak dapat dilakukan di darat (Nissim michal, 2014).

\section{METODE PENELITIAN}

Metode yang digunakan adalah studi tinjauan literatur (literature review) meliputi studi pencarian sistematis database terkomputerisasi: EBSCOHOST, Google Scholar dan Pubmed dalam bentuk jurnal penelitian berjumlah 10 jurnal yang diterbitkan sejak tahun 2010-2014. 10 jurnal menggunakan metode kuantitatif. Studi literatur ini mencoba memaparkan tentang aktifitas di air seperti berenang dan terapi air untuk pertumbuhan dan perkembangan bayi balita.

\section{HASIL DAN PEMBAHASAN}

Sebuah penelitian yang bertujuan untuk menilai efek dari terapi fisik dengan air pada peningkatan kualitas tidur dan pengurangan nyeri bayi prematur di NICU RS. Penelitian ini merupakan uji klinis terkontrol dengan sampel terdiri dari 12 bayi prematur (enam perempuan dan enam laki-laki) dengan rata-rata usia kehamilan 31,25 minggu. Kriteria inklusi adalah bayi prematur dengan kondisi stabil. Kriteria eksklusi adalah bayi prematur yang suhunya tidak stabil, kontraindikasi untuk mandi, masalah neurologis, membutuhkan ventilator, infeksi dan cacat bawaan. Suhu air dijaga pada 37 ${ }^{\circ} \mathrm{C}$ (Vignochi Carine, 2010).

Bayi yang memenuhi kriteria inklusi diberikan intervensi dengan terbungkus handuk di tubuh mereka semi-infleksi dan kemudian dengan lembut ditempatkan dalam lingkungan cair, dimana terapi fisik diterapkan selama 10 menit. Sebelum dilakukan terapi fisik air perilaku bayi bervariasi dari sepenuhnya terjaga dengan gerakan tubuh yang kuat untuk menangis. Setelah terapi fisik, bayi tidur nyenyak dan hanya beberapa gerakan tubuh. Terdapat perbedaan signifikan secara statistik ( $p<0,001)$. Skor pada skala penilaian nyeri juga menurun dari $5.38 \pm 0,91-0,25 \pm 0,46$, dengan $p$ $<0,001$ setelah intervensi, tanda-tanda vital tetap stabil (Vignochi Carine, 2010).

Lingkungan air memfasilitasi gerakan dan juga memungkinkan bayi untuk memulihkan perasaan gerakan 
fundamental mereka dan terus mengembangkan mereka gerakan motorik. Terapi fisik air terbukti aman dan efektif dalam mengurangi rasa sakit dan meningkatkan kualitas tidur bayi prematur di NICU. Intervensi ini, dapat digunakan sebagai metode nonfarmakologis untuk menghilangkan rasa sakit dan peningkatan kualitas tidur (Vignochi Carine, 2010).

Sebuah penelitian di Cina dengan tujuan menganalisa efek renang dan sentuhan pada neonatus ikterus fisiologis dalam waktu sepuluh hari kelahiran. Sampel penelitian adalah 110 bayi aterm dibagi menjadi 2 kelompok dengan 59 kasus pada kelompok perlakuan dan 51 kasus pada kelompok kontrol (Xiu-min Jiang, 2014).

Bayi dalam kelompok perlakuan diberikan berenang dan sentuhan selama 15 menit sekali tiap hari sedangkan bayi pada kelompok kontrol dilakukan mandi biasa sampai hari kesepuluh. Kemudian dilakukan pengukuran indeks warna kuning di dahi, dada dan perut dan mencatat waktu menyusui, buang air kecil dan buang air besar. Hasil perbedaan indeks penyakit kuning ratarata 24 jam pertama antara kedua kelompok tidak signifikan secara statistik (P> 0,05) sedangkan yang kedua, ketiga dan hari kesepuluh adalah signifikan $(\mathrm{P}<0,05)$. Perbedaan rata-rata waktu menyusui dan waktu eliminasi antara dua kelompok dari pertama sampai hari kesepuluh adalah signifikan $(\mathrm{P}<0,05)$. Berenang dan sentuhan meningkatkan volume asupan ASI dan eliminasi, serta menurunkan derajat ikterus pada bayi (Xiu-min Jiang, 2014).

Bakteri flora normal belum terbentuk di saluran usus pada bayi baru lahir, yang tidak dapat membuat conjugative bilirubin. Renang dapat meningkatkan pengeluaran energi, yang mendorong asupan makanan bertambah. Ini akan mempercepat pembentukan flora bakteri normal dalam saluran usus, membuat nyaman bagi bilirubin untuk kembali ke urobilinogen dan harus dikeluarkan dari tubuh. Tingkat bilirubin akan berkurang, sehingga mengurangi indeks ikterus pada bayi baru lahir (Xiu-min Jiang, 2014).

Kolam dapat mendorong motilitas saluran pencernaan bayi baru lahir, meningkatkan sekresi gastrin dan insulin, mempromosikan makanan untuk dicerna dan berasimilasi. Penelitian meningkatkan bahwa berenang meningkatkan nafsu makan 
bayi baru lahir. Meningkatnya jumlah berenang, bisa mempercepat keluarnya mekonium (Xiu-min Jiang, 2014).

Sebuah penelitian tahun 2013 bertujuan untuk menguji hubungan antara kemampuan motorik dan kemampuan bahasa. Penelitian ini melibatkan 94 balita. 31 balita berpartisipasi dalam kegiatan motorik air dibandingkan dengan 41 balita yang berpartisipasi dalam kegiatan motorik darat dan 21 balita yang berpartisipasi dalam kegiatan non-motorik.

Pada kelompok motorik air dilakukan di kolam hidroterapi (panjang 14 meter dan lebar 5 meter dengan suhu 33C. Kedalaman kolam berkisar $80 \mathrm{~cm}-$ $140 \mathrm{~cm})$. Satu pelatih renang disertai lima balita di dalam air. Balita belajar bagaimana mengontrol lingkungan air dalam kegiatan termasuk berdiri dan berjalan di air hingga dada, mengapungkan dada/perut, berguling dari perut ke belakang (dan sebaliknya) sambil menendang dengan kaki dan menggerakkan tangan, dan menyelam. Kelompok intervensi kedua adalah 45 balita dengan perlakuan basket, sepak bola, judo dan balet. Kelompok intervensi ketiga terdiri dari 33 balita dengan perlakuan catur, drama atau seni (Tsur Ronit Ram, 2013).
Setelah 6 bulan intervensi ditemukan hasil yang signifikan pada motorik kasar, motorik halus dan estimasi waktu kemampuan untuk kelompok kegiatan motorik air. Berdasarkan temuan-temuan ada hubungan antara kemampuan bahasa dan kemampuan motorik. Lingkungan air mengaktifkan kombinasi dari sistem vestibular dan sistem taktil (Tsur Ronit Ram, 2013).

Penelitian menyimpulkan bahwa aktivitas fisik meningkatkan keterampilan persepsi, kemampuan bahasa balita. Olahraga pada anak usia dini penting untuk pengembangan kesehatan kognitif. Setiap anak memiliki pola perkembangan yang unik dan pengembangan individu akan dipengaruhi oleh interaksi antara pengalaman hidup dan lingkungan. Air telah digunakan sepanjang sejarah untuk berbagai tujuan, termasuk terapi fisik, rehabilitasi dan olahraga (Nissim michal, 2014).

Berenang meningkatkan kemampuan keseimbangan tubuh sehingga memberikan lebih besar keselarasan tubuh dan stabilitas. Selain itu, integrasi sensorimotorik dapat dirangsang lebih efektif dalam lingkungan air dibandingkan dengan 
lingkungan di darat, karena air menyediakan tiga dimensi gerakanmaju-mundur, naik-turun dan kanan-kiri (Nissim michal, 2014).

\section{SIMPULAN DAN SARAN}

Upaya yang dapat dilakukan dalam mengoptimalkan tumbuh kembang bayi balita adalah dengan menyediakan lingkungan sebaik mungkin bagi mereka, agar mereka dapat tumbuh dan berkembang sesuai dengan potensi yang dimilikinya. Stimulasi adalah kegiatan merangsang kemampuan dasar anak agar anak tumbuh dan berkembang secara optimal. Setiap anak perlu mendapat stimulasi rutin sedini mungkin dan terus menerus pada setiap kesempatan. Stimulasi dapat diberikan oleh orang-orang terdekat. Berenang atau aktifitas air lainnya dapat meningkatkan kemampuan motorik kasar, motorik halus dan kemampuan bahasa pada balita. Berenang dan terapi air pada bayi balita dapat bermanfaat untuk mendukung pertumbuhan dan perkembangan bayi balita.

Dalam upaya peningkatan pencegahan penyimpangan tumbuh kembang anak balita maka perlu pemerataan program stimulasi, deteksi dini dan intervensi dini tumbuh kembang anak balita dan pemantauan tumbuh kembang secara berkala. Oleh sebab itu diharapkan peran serta aktif dari orang tua untuk memberikan stimulasi kepada bayi balita berupa terapi air dan berenang. Berenang atau aktifitas air lainnya dapat meningkatkan kemampuan motorik kasar, motorik halus dan kemampuan bahasa pada balita. Berenang dan terapi air pada bayi balita dapat bermanfaat untuk mendukung pertumbuhan dan perkembangan bayi balita. Adanya kemitraan antara keluarga (orang tua, pengasuh anak dan anggota keluarga lainnya), masyarakat (kader, organisasi profesi, lembaga swadaya masyarakat) dengan tenaga professional merupakan kunci untuk mengoptimalkan pertumbuhan dan perkembangan anak.

\section{DAFTAR PUSTAKA}

Feti, K. D., n.d. Efektifitas SDIDTK Terhadap Peningkatan Angka Penemuan Dini Gangguan Tumbuh Kembang Pada Anak Usia Balita Di Posyandu Teluk Wilayah Puskesmas Purwokerto Selatan.

Heribert L Stich, B. T. B. R. N. C. R. T. M. A. K., 2012. ndividual Development of Preschool Children-Prevalences and Determinants of Delays in 
Germany: A Cross-Sectional Study in Southern Bavaria.. MC Pediatrics, 12(188).

ID, W. P., 2012. Keterampilan Ibu Dalam Mendeteksi Dini Tumbuh Kembang Terhadap Tumbuh Kembang Bayi. jurnal STIKES, Volume 1.

Jeharsae R, S. R. W. W. C. V., 2013. Growth and development of children aged $1-5$ years in low-intensity armed conflict areas in Southern Thailand: a community-based survey. BioMed Central, 7(8).

Laura E. Murray-Kolb, Z. A. R. R. J. S. e., 2014. The MAL-ED Cohort Study: Methods and Lessons Learned When Assessing Early Child and Caregiving Mediators in Infants and Young Children in 8 Low- and MiddleIncome Countries. Methods to Assess Child Development in 8 LMICs. Volume 59.

Nissim michal, e. a., 2014. Effects of Aquatic Motor Activities on Early Childhood Cognitive and Motor Development. Open Journal of Social
Sciences, Volume 2, pp. 2439.

ShamsB, G. P. N. A., 2013. The evaluation of Mothers' participation project in children's growth and development process: Using the CIPP evaluation model.. $J$ Educ Health Promot. , 2(21).

Tsur Ronit Ram, e. a., 2013. Language Development: The Effect of Aquatic and On-Land Motor Interventions. SciRes, 4(9), pp. 41-50.

Vignochi Carine, e. a., 2010. ffect of aquatic physical therapy on pain and state of sleep and wakefulness among stable preterm newborns in neonatal intensive care units. Rev Bras Fisioter, São Carlos, 14(3), pp. 214-220.

Xiu-min Jiang, e. a., 2014. Effects of Swimming and Touching on Physiological Jaundice of Neonates within ten days of birth. Life Science Journal , 11(7). 